\title{
A $k$-Dimensional System of Fractional Neutral Functional Differential Equations with Bounded Delay
}

\author{
Dumitru Baleanu, ${ }^{1,2,3}$ Sayyedeh Zahra Nazemi, ${ }^{4}$ and Shahram Rezapour ${ }^{4}$ \\ ${ }^{1}$ Department of Chemical and Materials Engineering, Faculty of Engineering, King Abdulaziz University, \\ P.O. Box 80204, Jeddah 21589, Saudi Arabia \\ ${ }^{2}$ Department of Mathematics, Cankaya University, Ogretmenler Caddesi 14, Balgat, 06530 Ankara, Turkey \\ ${ }^{3}$ Institute of Space Sciences, Magurele, 76900 Bucharest,Romania \\ ${ }^{4}$ Department of Mathematics, Azarbaijan Shahid Madani University, Azarshahr, Tabriz, Iran
}

Correspondence should be addressed to Dumitru Baleanu; dumitru.baleanu@gmail.com

Received 6 October 2013; Accepted 15 March 2014; Published 10 April 2014

Academic Editor: M. Mursaleen

Copyright ( 2014 Dumitru Baleanu et al. This is an open access article distributed under the Creative Commons Attribution License, which permits unrestricted use, distribution, and reproduction in any medium, provided the original work is properly cited.

In 2010, Agarwal et al. studied the existence of a one-dimensional fractional neutral functional differential equation. In this paper, we study an initial value problem for a class of $k$-dimensional systems of fractional neutral functional differential equations by using Krasnoselskii's fixed point theorem. In fact, our main result generalizes their main result in a sense.

\section{Introduction}

As you know, many researchers are interested in developing the theoretical analysis and numerical methods of fractional equations, because different applications of this area have been founded in various fields of sciences and engineering (see, e.g., [1-37]). In this paper, we investigate the initial value problem of a $k$-dimensional system of fractional neutral functional differential equations with bounded delay:

$$
\begin{gathered}
{ }^{c} D^{\alpha_{1}}\left(x_{1}(t)-g_{1}\left(t, \mathbf{x}_{\mathbf{t}}\right)\right)=f_{1}\left(t, \mathbf{x}_{\mathbf{t}}\right), \\
{ }^{c} D^{\alpha_{2}}\left(x_{2}(t)-g_{2}\left(t, \mathbf{x}_{\mathbf{t}}\right)\right)=f_{2}\left(t, \mathbf{x}_{\mathbf{t}}\right), \\
\vdots \\
{ }^{c} D^{\alpha_{k}}\left(x_{k}(t)-g_{k}\left(t, \mathbf{x}_{\mathbf{t}}\right)\right)=f_{k}\left(t, \mathbf{x}_{\mathbf{t}}\right), \\
x_{1_{t_{0}}}=\phi_{1}, \quad x_{t_{t_{0}}}=\phi_{2}, \ldots, x_{k_{t_{0}}}=\phi_{k},
\end{gathered}
$$

where $t_{0} \geq 0, a>0$, and $r>0$ are constants, $t \in$ $\left(t_{0}, \infty\right), 0<\alpha_{i}<1$, for $i=1,2, \ldots, k,{ }^{c} D$ is the standard Caputo's fractional derivative, $f_{i}, g_{i}:\left[t_{0}, \infty\right) \times C\left([-r, 0], \mathbb{R}^{n}\right) \times$ $C\left([-r, 0], \mathbb{R}^{n}\right) \times \cdots \times C\left([-r, 0], \mathbb{R}^{n}\right) \rightarrow \mathbb{R}^{n}$ are given functions $(i=1,2, \ldots, k)$ satisfying some assumptions that will be specified later, $\mathbf{x}_{\mathbf{t}}=\left(x_{1_{t}}, x_{2_{t}}, \ldots, x_{k_{t}}\right)$, and $\phi_{i} \in C\left([-r, 0], \mathbb{R}^{n}\right)$ for $i=1,2, \ldots, k$. If $x \in C\left(\left[t_{0}-r, t_{0}+a\right], \mathbb{R}^{n}\right)$, then for each $t \in\left[t_{0}, t_{0}+a\right]$ define $x_{t}$ by $x_{t}(\theta)=x(t+\theta)$ for all $\theta \in[-r, 0]$. One-dimensional version of the problem has been studied by Agarwal et al. (see [4]). We show that the problem (1) is equivalent to an integral equation and by using Krasnoselskii's fixed point theorem, we conclude that the equivalent operator has (at least) a fixed point. This implies that the problem (1) has at least one solution. One can find the following lemma in [38].

Lemma 1 (Krasnoselskii's fixed point theorem). Let $X$ be a Banach space and $E$ a closed convex subset of $X$. Suppose that $S$ and $U$ are two maps of $E$ into $X$ such that $S x+U y \in E$ for all $x, y \in E$. If $S$ is a contraction and $U$ is completely continuous, then the equation $S x+U x=x$ has a solution on $E$.

Let $I$ be an interval in $\mathbb{R}$ and $X=C\left(I, \mathbb{R}^{n}\right)$ with the norm $\|x\|=\sup _{t \in I}|x(t)|$, where $|\cdot|$ denotes a suitable complete norm on $\mathbb{R}^{n}$. Consider the product Banach space $\left(X^{k}=\right.$ $\underbrace{X \times X \times \cdots \times X},\|\cdot\|_{*})$ with the norm $\left\|\left(x_{1}, x_{2}, \ldots, x_{k}\right)\right\|_{*}=$ $\max \left\{\left\|x_{1}\right\|,\left\|x_{2}\right\|, \ldots,\left\|x_{k}\right\|\right\}$. The fractional integral of order $q$ 
with the lower limit $t_{0}$ for a function $f$ is defined by $I^{q} f(t)=$ $(1 / \Gamma(q)) \int_{t_{0}}^{t}\left(f(s) /(t-s)^{1-q}\right) d s$ for $t>t_{0}$ and $q>0$, provided the right-hand side is pointwise defined on $\left[t_{0}, \infty\right)$. Here, $\Gamma$ is the gamma function. Also, Caputo's derivative of order $q$ with the lower limit $t_{0}$ for a function $f:\left[t_{0}, \infty\right) \rightarrow \mathbb{R}$ is defined by

$$
{ }^{c} D^{q} f(t)=\frac{1}{\Gamma(n-q)} \int_{t_{0}}^{t} \frac{f^{(n)}(s)}{(t-s)^{q+1-n}} d s=I^{n-q} f^{(n)}(t)
$$

for $t>t_{0}$ and $n-1<q<n([34])$.

\section{Main Results}

Consider the problem (1). Let $\delta$ and $\gamma$ be positive constants, $I_{0}=\left[t_{0}, t_{0}+\delta\right]$, and

$$
\begin{aligned}
A(\delta, \gamma)=\left\{\left(x_{1}, x_{2}, \ldots, x_{k}\right): x_{i_{t_{0}}}=\phi_{i},\right. & \\
& \left.\sup _{t_{0} \leq t \leq t_{0}+\delta}\left|x_{i}(t)-\phi_{i}(0)\right| \leq \gamma, \forall i=1,2, \ldots, k\right\},
\end{aligned}
$$

where $x_{i} \in C\left(\left[t_{0}-r, t_{0}+\delta\right], \mathbb{R}^{n}\right)$. For obtaining our results, we need the following conditions:

$\left(\mathrm{H}_{1}\right) f_{i}\left(t, \varphi_{1}, \varphi_{2}, \ldots, \varphi_{k}\right)$ is measurable with respect to $t$ on $I_{0}$ for all $i=1,2, \ldots, k$,

$\left(\mathrm{H}_{2}\right) f_{i}\left(t, \varphi_{1}, \varphi_{2}, \ldots, \varphi_{k}\right)$ is continuous with respect to $\varphi_{j}$ on $C\left([-r, 0], \mathbb{R}^{n}\right)$ for all $i, j=1,2, \ldots, k$,

$\left(\mathrm{H}_{3}\right)$ there exist $\alpha_{i 1} \in\left(0, \alpha_{i}\right)$ and a real-valued function $m_{i}(t) \in L^{1 / \alpha_{i 1}}\left(I_{0}\right)$ such that

$$
\left|f_{i}\left(t, \mathbf{x}_{\mathbf{t}}\right)\right| \leq m_{i}(t)
$$

for all $\left(x_{1}, x_{2}, \ldots, x_{k}\right) \in A(\delta, \gamma), t \in I_{0}$, and $i=$ $1,2, \ldots, k$,

$\left(\mathrm{H}_{4}\right) g_{i}\left(t, \mathbf{x}_{\mathbf{t}}\right)=g_{i 1}\left(t, \mathbf{x}_{\mathbf{t}}\right)+g_{i 2}\left(t, \mathbf{x}_{\mathbf{t}}\right)$ for all $\left(x_{1}, x_{2}, \ldots, x_{k}\right) \in$ $A(\delta, \gamma)$,

$\left(\mathrm{H}_{5}\right) g_{i 1}$ is continuous and

$$
\left|g_{i 1}\left(t, \mathbf{x}_{\mathbf{t}}\right)-g_{i 1}\left(t, \mathbf{y}_{\mathbf{t}}\right)\right| \leq l_{i}\|x-y\|_{*}
$$

for all $x=\left(x_{1}, x_{2}, \ldots, x_{k}\right), y=\left(y_{1}, y_{2}, \ldots, y_{k}\right) \in$ $A(\delta, \gamma)$, and $t \in I_{0}$, where $l_{i} \in(0,1)$ is a constant, for all $i=1,2, \ldots, k$,

$\left(\mathrm{H}_{6}\right) g_{i 2}$ is completely continuous and the family $\{t \quad \vdash$ $\left.g_{i 2}\left(t, \mathbf{x}_{\mathbf{t}}\right):\left(x_{1}, x_{2}, \ldots, x_{k}\right) \in \Lambda\right\}$ is equicontinuous on $\underbrace{C\left(I_{0}, \mathbb{R}^{n}\right) \times C\left(I_{0}, \mathbb{R}^{n}\right) \times \cdots \times C\left(I_{0}, \mathbb{R}^{n}\right)}_{k}$ for all bounded set $\Lambda$ in $A(\delta, \lambda)$ and $i=1,2, \ldots, k$.

Lemma 2. Suppose that there exist $\delta \in(0, a)$ and $\gamma \in(0, \infty)$ such that $\left(H_{1}\right)-\left(H_{3}\right)$ hold. Then the problem (1) for $t \in\left(t_{0}, t_{0}+\right.$ $\delta$ ] is equivalent to the equation

$$
\begin{aligned}
x_{i}(t)= & \phi_{i}(0)-g_{i}\left(t_{0}, \phi_{1}, \phi_{2}, \ldots, \phi_{k}\right)+g_{i}\left(t, \mathbf{x}_{\mathbf{t}}\right) \\
& +\frac{1}{\Gamma\left(\alpha_{i}\right)} \int_{t_{0}}^{t}(t-s)^{\alpha_{i}-1} f_{i}\left(s, \mathbf{x}_{\mathbf{s}}\right) d s
\end{aligned}
$$

with conditions $x_{i_{t_{0}}}=\phi_{i}$ for $i=1,2, \ldots, k$ and $t \in I_{0}$.
Proof. It is easy to see that $f_{i}\left(t, \mathbf{x}_{\mathbf{t}}\right)$ is Lebesgue measurable on $I_{0}$ by using conditions $\left(\mathrm{H}_{1}\right)$ and $\left(\mathrm{H}_{2}\right)$ for all $i=$ $1,2, \ldots, k$. Also, a direct calculation shows that $(t-s)^{\alpha_{i}-1} \in$ $L^{1 /\left(1-\alpha_{i 1}\right)}\left(\left[t_{0}, t\right]\right)$ for $t \in I_{0}$. By using Holder's inequality and condition $\left(\mathrm{H}_{3}\right)$, we get that $(t-s)^{\alpha_{i}-1} f_{i}\left(s, \mathbf{x}_{\mathbf{s}}\right)$ is Lebesgue integrable with respect to $s \in\left[t_{0}, t\right]$ for all $t \in I_{0}, i=$ $1,2, \ldots, k$, and $\left(x_{1}, x_{2}, \ldots, x_{k}\right) \in A(\delta, \gamma)$, and

$$
\begin{aligned}
\int_{t_{0}}^{t}\left|(t-s)^{\alpha_{i}-1} f_{i}\left(s, \mathbf{x}_{\mathbf{s}}\right)\right| d s & \\
& \leq\left\|(t-s)^{\alpha_{i}-1}\right\|_{L^{1 /\left(1-\alpha_{i 1}\right)}\left(\left[t_{0}, t\right]\right)}\left\|m_{i}\right\|_{L^{1 / \alpha_{i 1}\left(I_{0}\right)}} .
\end{aligned}
$$

It is easy to see that if $x=\left(x_{1}, x_{2}, \ldots, x_{k}\right)$ is a solution of the problem (1), then $x$ is a solution of $(*)$. Now, suppose that $x=\left(x_{1}, x_{2}, \ldots, x_{k}\right)$ is a solution of the equation $(*)$ and $t \in\left(t_{0}, t_{0}+\delta\right]$. Then $x_{i_{0}}=\phi_{i}$ and ${ }^{c} D^{\alpha_{i}}\left(x_{i}(t)-g_{i}\left(t, \mathbf{x}_{\mathbf{t}}\right)\right)=$ $f_{i}\left(t, \mathbf{x}_{\mathbf{t}}\right)$ for all $t \in\left(t_{0}, t_{0}+\delta\right]$ and $i=1,2, \ldots, k$. Thus, $x=\left(x_{1}, x_{2}, \ldots, x_{k}\right)$ is a solution of the problem (1). This completes the proof.

Theorem 3. Suppose that there exist $\delta \in(0, a)$ and $\gamma \in(0, \infty)$ such that $\left(H_{1}\right)-\left(H_{6}\right)$ hold. Then the problem (1) has at least one solution on $\left[t_{0}, t_{0}+\eta\right]$ for some positive number $\eta$.

Proof. Since condition $\left(\mathrm{H}_{4}\right)$ holds, the equation $(*)$ is equivalent to the equation

$$
\begin{aligned}
x_{i}(t)= & \phi_{i}(0)-g_{i 1}\left(t_{0}, \phi_{1}, \phi_{2}, \ldots, \phi_{k}\right) \\
& -g_{i 2}\left(t_{0}, \phi_{1}, \phi_{2}, \ldots, \phi_{k}\right)+g_{i 1}\left(t, \mathbf{x}_{\mathbf{t}}\right)+g_{i 2}\left(t, \mathbf{x}_{\mathbf{t}}\right) \\
& +\frac{1}{\Gamma\left(\alpha_{i}\right)} \int_{t_{0}}^{t}(t-s)^{\alpha_{i}-1} f_{i}\left(s, \mathbf{x}_{\mathbf{s}}\right) d s
\end{aligned}
$$

and $x_{i_{t_{0}}}=\phi_{i}$ for all $t \in I_{0}$ and $i=1,2, \ldots, k$. Let $\left(\widetilde{\phi}_{1}, \widetilde{\phi}_{2}, \ldots, \widetilde{\phi}_{k}\right) \in A(\delta, \gamma)$ be defined by $\widetilde{\phi}_{i_{t_{0}}}=\phi_{i}$ and $\widetilde{\phi}_{i}\left(t_{0}+\right.$ $t)=\phi_{i}(0)$ for all $t \in[0, \delta]$ and $i=1,2, \ldots, k$. If $x=$ $\left(x_{1}, x_{2}, \ldots, x_{k}\right)$ is a solution of problem (1) and $x_{i}\left(t_{0}+t\right)=$ $\widetilde{\phi}_{i}\left(t_{0}+t\right)+y_{i}(t)$ for $t \in[-r, \delta]$ and $i=1,2, \ldots, k$, then $x_{i_{t_{0}+t}}=\widetilde{\phi}_{i_{t_{0}+t}}+y_{i_{t}}$ for $t \in[0, \delta]$ and $i=1,2, \ldots, k$. Thus,

$$
\begin{aligned}
y_{i}(t)= & -g_{i 1}\left(t_{0}, \phi_{1}, \phi_{2}, \ldots, \phi_{k}\right)-g_{i 2}\left(t_{0}, \phi_{1}, \phi_{2}, \ldots, \phi_{k}\right) \\
& +g_{i 1}\left(t_{0}+t, y_{1_{t}}+\widetilde{\phi}_{1_{t_{0}+t}}, y_{2_{t}}+\widetilde{\phi}_{2_{t_{0}+t}}, \ldots, y_{k_{t}}+\widetilde{\phi}_{k_{t_{0}+t}}\right) \\
& +g_{i 2}\left(t_{0}+t, y_{1_{t}}+\widetilde{\phi}_{1_{t_{0}+t}}, y_{2_{t}}+\widetilde{\phi}_{2_{t_{0}+t}}, \ldots, y_{k_{t}}+\widetilde{\phi}_{k_{t_{0}+t}}\right) \\
& +\frac{1}{\Gamma(\alpha)} \int_{0}^{t}(t-s)^{\alpha_{i}-1} f_{i}\left(t_{0}+s, y_{1_{s}}+\widetilde{\phi}_{1_{t_{0}+s}}, y_{2_{s}}\right. \\
& \left.+\widetilde{\phi}_{t_{t_{0}+s}}, \ldots, y_{k_{s}}+\widetilde{\phi}_{k_{t_{0}+s}}\right) d s
\end{aligned}
$$

for $t \in[0, \delta]$ and $i=1,2, \ldots, k$. Since $g_{i 1}, g_{i 2}$ are continuous and $x_{i_{t}}$ is continuous in $t$ for all $i=1,2, \ldots, k$, there exists $\delta^{\prime}>0$ such that $\mid g_{i 1}\left(t_{0}+t, y_{1_{t}}+\tilde{\phi}_{1_{t_{0}+t}}, y_{2_{t}}+\tilde{\phi}_{2_{t_{0}+t}}, \ldots, y_{k_{t}}+\right.$ 
$\left.\widetilde{\phi}_{k_{t_{0}+t}}\right)-g_{i 1}\left(t_{0}, \phi_{1}, \phi_{2}, \ldots, \phi_{k}\right) \mid<\gamma / 3$ and $\mid g_{i 2}\left(t_{0}+t, y_{1_{t}}+\right.$ $\left.\widetilde{\phi}_{t_{t_{0}+t}}, y_{2_{t}}+\widetilde{\phi}_{t_{t_{0}+t}}, \ldots, y_{k_{t}}+\widetilde{\phi}_{k_{t_{0}+t}}\right)-g_{i 2}\left(t_{0}, \phi_{1}, \phi_{2}, \ldots, \phi_{k}\right) \mid<$ $\gamma / 3$ for $0<t<\delta^{\prime}$ and $i=1,2, \ldots, k$. Put $\eta=$ $\min _{1 \leq i \leq k}\left\{\delta, \delta^{\prime},\left(\gamma \Gamma\left(\alpha_{i}\right)\left(1+\beta_{i}\right)^{1-\alpha_{i 1}} / 3 M_{i}\right)^{1 /\left(1+\beta_{i}\right)\left(1-\alpha_{i 1}\right)}\right\}$, where $\beta_{i}=\left(\alpha_{i}-1\right) /\left(1-\alpha_{i 1}\right) \in(-1,0)$ and $M_{i}=\left\|m_{i}\right\|_{L^{1 / \alpha_{i 1}\left(I_{0}\right)}}$ for all $i=1,2, \ldots, k$. Define

$E(\eta, \gamma)=\left\{\left(y_{1}, y_{2}, \ldots, y_{k}\right): y_{i} \in C\left([-r, \eta], \mathbb{R}^{n}\right), y_{i}(s)=0\right.$,

$\left\|y_{i}\right\| \leq \gamma$ for $\left.s \in[-r, 0], i=1,2, \ldots, k\right\}$.

In fact, $E(\eta, \gamma)$ is a closed, bounded, and convex subset of $C\left([-r, \eta], \mathbb{R}^{n}\right) \times C\left([-r, \eta], \mathbb{R}^{n}\right) \times \cdots \times C\left([-r, \eta], \mathbb{R}^{n}\right)$. Define the operators $S$ and $U$ on $E(\eta, \gamma)$ by

$$
\begin{gathered}
S\left(y_{1}, y_{2}, \ldots, y_{k}\right)(t)=\left(\begin{array}{c}
S_{1}\left(y_{1}, y_{2}, \ldots, y_{k}\right)(t) \\
S_{2}\left(y_{1}, y_{2}, \ldots, y_{k}\right)(t) \\
\vdots \\
S_{k}\left(y_{1}, y_{2}, \ldots, y_{k}\right)(t)
\end{array}\right), \\
U\left(y_{1}, y_{2}, \ldots, y_{k}\right)(t)=\left(\begin{array}{c}
U_{1}\left(y_{1}, y_{2}, \ldots, y_{k}\right)(t) \\
U_{2}\left(y_{1}, y_{2}, \ldots, y_{k}\right)(t) \\
\vdots \\
U_{k}\left(y_{1}, y_{2}, \ldots, y_{k}\right)(t)
\end{array}\right),
\end{gathered}
$$

where

$$
\begin{aligned}
& S_{i}\left(y_{1}, y_{2}, \ldots, y_{k}\right)(t) \\
& =\left\{\begin{array}{lc}
0 & t \in[-r, 0], \\
-g_{i 1}\left(t_{0}, \phi_{1}, \phi_{2}, \ldots, \phi_{k}\right) & \\
+g_{i 1}\left(t_{0}+t, y_{1_{t}}+\widetilde{\phi}_{t_{t^{+t}},}, y_{2_{t}}\right. & \\
\left.\quad+\widetilde{\phi}_{\left.2_{t_{0}+t}, \ldots, y_{k_{t}}+\widetilde{\phi}_{k_{t_{0}+t}}\right)}\right) & t \in[0, \eta],
\end{array}\right. \\
& U_{i}\left(y_{1}, y_{2}, \ldots, y_{k}\right)(t) \\
& =\left\{\begin{array}{lc}
0 & t \in[-r, 0], \\
-g_{i 2}\left(t_{0}, \phi_{1}, \phi_{2}, \ldots, \phi_{k}\right) & \\
\quad+g_{i 2}\left(t_{0}+t, y_{1_{t}}+\widetilde{\phi}_{t_{t_{0}+t}}, y_{2_{t}}\right. & \\
\left.\quad+\widetilde{\phi}_{t_{t_{0}+t}}, \ldots, y_{k_{t}}+\widetilde{\phi}_{k_{t_{0}+t}}\right) & \\
\quad+\frac{1}{\Gamma\left(\alpha_{i}\right)} \int_{0}^{t}(t-s)^{\alpha_{i}-1} & \\
\quad \times f_{i}\left(t_{0}+s, y_{1_{s}}+\widetilde{\phi}_{1_{t_{0}+s}}, y_{2_{s}}\right. \\
\left.\quad+\widetilde{\phi}_{2_{t_{0}+s}}, \ldots, y_{k_{s}}+\widetilde{\phi}_{k_{t_{0}+s}}\right) d s & t \in[0, \eta],
\end{array}\right.
\end{aligned}
$$

for $i=1,2, \ldots, k$. It is easy to check that the operator equation $y=S y+U y$ has a solution $y=\left(y_{1}, y_{2}, \ldots, y_{k}\right)$ if and only if $y_{i}$ is a solution for $(* *)$ for all $i=1,2, \ldots, k$. In this case, $x_{i}\left(t_{0}+t\right)=y_{i}(t)+\widetilde{\phi}_{i}\left(t_{0}+t\right)$ will be a solution of the problem (1) on $[0, \eta]$. Thus, the existence of a solution of the problem (1) is equivalent to the existence of a fixed point for the operator
$S+U$ on $E(\eta, \gamma)$. Hence, it is sufficient that we show that $S+U$ has a fixed point in $E(\eta, \gamma)$. We prove it in three steps.

Step I. Sz+Uy $\in E(\eta, \gamma)$ for all $z=\left(z_{1}, z_{2}, \ldots, z_{k}\right), y=$ $\left(y_{1}, y_{2}, \ldots, y_{k}\right) \in E(\eta, \gamma)$.

Let $z, y \in E(\eta, \gamma)$ be given. Then, $S_{i} z+U_{i} y \in$ $C\left([-r, \eta], \mathbb{R}^{n}\right)$ for all $i=1,2, \ldots, k$. It is easy to check that $(S z+U y)(t)=0$ for all $t \in[-r, 0]$. Also, we have

$$
\begin{aligned}
& \mid S_{i} z(t)+U_{i} y(t) \mid \\
& \leq \mid-g_{i 1}\left(t_{0}, \phi_{1}, \phi_{2}, \ldots, \phi_{k}\right) \\
&+g_{i 1}\left(t_{0}+t, z_{1_{t}}+\widetilde{\phi}_{1_{t_{0}+t}}, z_{2_{t}}+\widetilde{\phi}_{2_{t_{0}+t}}, \ldots, z_{k_{t}}+\widetilde{\phi}_{k_{t_{0}+t}}\right) \mid \\
&+ \mid-g_{i 2}\left(t_{0}, \phi_{1}, \phi_{2}, \ldots, \phi_{k}\right) \\
&+g_{i 2}\left(t_{0}+t, y_{1_{t}}+\widetilde{\phi}_{t_{t_{0}+t}}, y_{2_{t}}+\widetilde{\phi}_{t_{t_{0}+t}}, \ldots, y_{k_{t}}+\widetilde{\phi}_{k_{t_{0}+t}}\right) \mid \\
&+\frac{1}{\Gamma\left(\alpha_{i}\right)} \int_{0}^{t} \mid(t-s)^{\alpha_{i}-1} f_{i}\left(t_{0}+s, y_{1_{s}}+\widetilde{\phi}_{t_{t_{0}+s}}, y_{2_{s}}\right. \\
& \leq \frac{2 \gamma}{3}+\frac{1}{\Gamma\left(\alpha_{i}\right)}\left(\int_{2_{t_{0}+s}}, \ldots, y_{k_{s}}+\widetilde{\phi}_{k_{t_{0}+s}}\right) \mid d s \\
&\left.\quad \times\left(\int_{t_{0}}^{t_{0}+t}\left(m_{i}(s)\right)^{1 / \alpha_{i 1}} d s\right)^{\left(\alpha_{i}-1\right) /\left(1-\alpha_{i 1}\right)} d s\right)^{1-\alpha_{i 1}} \\
& \leq \frac{2 \gamma}{3}+\frac{M_{i} \eta^{\left(1+\beta_{i}\right)\left(1-\alpha_{i 1}\right)}}{\Gamma\left(\alpha_{i}\right)\left(1+\beta_{i}\right)^{1-\alpha_{i 1}} \leq \gamma}
\end{aligned}
$$

for all $t \in[0, \eta]$ and $i=1,2, \ldots, k$. Thus, $\left\|S_{i} z+U_{i} y\right\|=$ $\sup _{t \in[0, \eta]}\left|\left(S_{i} z\right)(t)-\left(U_{i} y\right)(t)\right| \leq \gamma$ for all $i=1,2, \ldots, k$. Hence, $S z+U y \in E(\eta, \gamma)$ for all $z, y \in E(\eta, \gamma)$.

Step II. S is a contraction on $E(\eta, \gamma)$. Then,

Let $y^{\prime}=\left(y_{1}^{\prime}, y_{2}^{\prime}, \ldots, y_{k}^{\prime}\right), y^{\prime \prime}=\left(y_{1}^{\prime \prime}, y_{2}^{\prime \prime}, \ldots, y_{k}^{\prime \prime}\right) \in E(\eta, \gamma)$.

$$
\begin{gathered}
\left(y_{1_{t}}^{\prime}+\widetilde{\phi}_{1_{t_{0}+t}}, y_{2_{t}}^{\prime}+\widetilde{\phi}_{t_{t_{0}+t}}, \ldots, y_{k_{t}}^{\prime}+\widetilde{\phi}_{k_{t_{0}+t}}\right), \\
\left(y_{1_{t}}^{\prime \prime}+\widetilde{\phi}_{1_{t_{0}+t}}, y_{2_{t}}^{\prime \prime}+\widetilde{\phi}_{t_{t_{0}+t}}, \ldots, y_{k_{t}}^{\prime \prime}+\widetilde{\phi}_{k_{t_{0}+t}}\right) \in A(\delta, \gamma)
\end{gathered}
$$

and so

$$
\begin{aligned}
& \left|S_{i} y^{\prime}(t)-S_{i} y^{\prime \prime}(t)\right| \\
& =\mid g_{i 1}\left(t_{0}+t, y_{1_{t}}^{\prime}+\widetilde{\phi}_{1_{t_{0}+t}}, y_{2_{t}}^{\prime}+\widetilde{\phi}_{2_{t_{0}+t}}, \ldots, y_{k_{t}}^{\prime}+\widetilde{\phi}_{k_{t_{0}+t}}\right) \\
& \quad-g_{i 1}\left(t_{0}+t, y_{1_{t}}^{\prime \prime}+\widetilde{\phi}_{1_{t_{0}+t}}, y_{2_{t}}^{\prime \prime}\right. \\
& \left.\quad+\widetilde{\phi}_{2_{t_{0}+t}}, \ldots, y_{k_{t}}^{\prime \prime}+\widetilde{\phi}_{k_{t_{0}+t}}\right) \mid \\
& \leq l_{i}\left\|y^{\prime}-y^{\prime \prime}\right\|_{*}
\end{aligned}
$$


for all $i=1,2, \ldots, k$. This implies that $\left\|S y^{\prime}-S y^{\prime \prime}\right\|_{*} \leq$ $l\left\|y^{\prime}-y^{\prime \prime}\right\|_{*}$, where $l=\max \left\{l_{1}, l_{2}, \ldots, l_{k}\right\}$. Since $0<l<1$, $S$ is a contraction on $E(\eta, \gamma)$.

Step III.U is a completely continuous operator.

Suppose that

$$
\begin{aligned}
& U_{i 1}\left(y_{1}, y_{2}, \ldots, y_{k}\right)(t)
\end{aligned}
$$

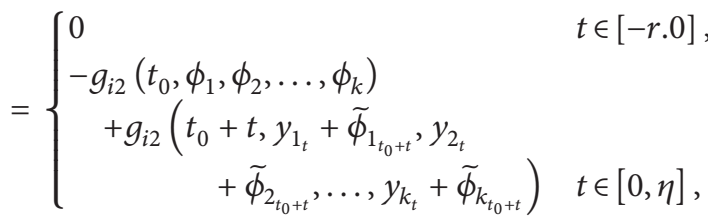

$$
\begin{aligned}
& U_{i 2}\left(y_{1}, y_{2}, \ldots, y_{k}\right)(t) \\
& =\left\{\begin{array}{cc}
0 & t \in[-r .0], \\
\frac{1}{\Gamma\left(\alpha_{i}\right)} \int_{0}^{t}(t-s)^{\alpha_{i}-1} & \\
\quad \times f_{i}\left(t_{0}+s, y_{1_{s}}+\widetilde{\phi}_{1_{t_{0}+s}}, y_{2_{s}}\right. \\
\left.\quad+\widetilde{\phi}_{2_{t_{0}+s}}, \ldots, y_{k_{s}}+\tilde{\phi}_{k_{t_{0}+s}}\right) d s & t \in[0, \eta],
\end{array}\right.
\end{aligned}
$$

for $i=1,2, \ldots, k$. It is clear that

$$
U=\left(\begin{array}{c}
U_{11}+U_{12} \\
U_{21}+U_{22} \\
\vdots \\
U_{k 1}+U_{k 2}
\end{array}\right)
$$

Since $g_{i 2}$ is completely continuous for all $i=1,2, \ldots, k$, $U_{i 1}$ is continuous and also $\left\{U_{i 1}(y): y \in E(\eta, \gamma)\right\}$ is uniformly bounded. By using condition $\left(\mathrm{H}_{6}\right)$, it is easy to check that $\left\{U_{i 1}(y): y \in E(\eta, \gamma)\right\}$ is equicontinuous. On the other hand,

$$
\begin{aligned}
& \left|U_{i 2} y(t)\right| \\
& \leq \frac{1}{\Gamma\left(\alpha_{i}\right)} \int_{0}^{t}(t-s)^{\alpha_{i}-1} \mid f_{i}\left(t_{0}+s, y_{1_{s}}+\widetilde{\phi}_{1_{t_{0}+s}}, y_{2_{s}}\right. \\
& \left.+\widetilde{\phi}_{2_{t_{0}+s}}, \ldots, y_{k_{s}}+\widetilde{\phi}_{k_{t_{0}+s}}\right) \mid d s \\
& \leq \frac{1}{\Gamma\left(\alpha_{i}\right)}\left(\int_{0}^{t}(t-s)^{\left(\alpha_{i}-1\right) /\left(1-\alpha_{i 1}\right)} d s\right)^{1-\alpha_{i 1}} \\
& \quad \times\left(\int_{t_{0}}^{t_{0}+t}\left(m_{i}(s)\right)^{1 / \alpha_{i 1}} d s\right)^{\alpha_{i 1}} \leq \frac{M_{i} \eta^{\left(1+\beta_{i}\right)\left(1-\alpha_{i 1}\right)}}{\Gamma\left(\alpha_{i}\right)\left(1+\beta_{i}\right)^{1-\alpha_{i 1}}}
\end{aligned}
$$

for all $t \in[0, \eta]$ and $i=1,2, \ldots, k$. This implies that $\left\{U_{i 2} y\right.$ : $y \in E(\eta, \gamma)\}$ is uniformly bounded. Now, we prove that $\left\{U_{i 2} y\right.$ : $y \in E(\eta, \gamma)\}$ is equicontinuous. Let $0 \leq t_{1}<t_{2} \leq \eta$ and $y \in E(\eta, \gamma)$ be given. Then, we have

$$
\begin{aligned}
& \left|U_{i 2} y\left(t_{2}\right)-U_{i 2} y\left(t_{1}\right)\right| \\
& =\mid \frac{1}{\Gamma\left(\alpha_{i}\right)} \int_{0}^{t_{1}}\left[\left(t_{2}-s\right)^{\alpha_{i}-1}-\left(t_{1}-s\right)^{\alpha_{i}-1}\right] \\
& \times f_{i}\left(t_{0}+s, y_{1_{s}}+\widetilde{\phi}_{1_{t_{0}+s}}, y_{2_{s}}\right. \\
& \left.+\widetilde{\phi}_{2_{t_{0}+s}}, \ldots, y_{k_{s}}+\widetilde{\phi}_{k_{t_{0}+s}}\right) d s \\
& +\frac{1}{\Gamma\left(\alpha_{i}\right)} \int_{t_{1}}^{t_{2}}\left(t_{2}-s\right)^{\alpha_{i}-1} f_{i}\left(t_{0}+s, y_{1_{s}}+\widetilde{\phi}_{1_{t_{0}+s}}, y_{2_{s}}\right. \\
& \left.+\widetilde{\phi}_{2_{t_{0}+s}}, \ldots, y_{k_{s}}+\widetilde{\phi}_{k_{t_{0}+s}}\right) d s \\
& \leq \frac{1}{\Gamma\left(\alpha_{i}\right)} \int_{0}^{t_{1}}\left[\left(t_{1}-s\right)^{\alpha_{i}-1}-\left(t_{2}-s\right)^{\alpha_{i}-1}\right] \\
& \times \mid f_{i}\left(t_{0}+s, y_{1_{s}}+\widetilde{\phi}_{1_{t_{0}+s}}, y_{2_{s}}\right. \\
& \left.+\widetilde{\phi}_{t_{t_{0}+s}}, \ldots, y_{k_{s}}+\widetilde{\phi}_{k_{t_{0}+s}}\right) \mid d s \\
& +\frac{1}{\Gamma\left(\alpha_{i}\right)} \int_{t_{1}}^{t_{2}}\left(t_{2}-s\right)^{\alpha_{i}-1} \mid f_{i}\left(t_{0}+s, y_{1_{s}}+\widetilde{\phi}_{1_{t_{0}+s}}, y_{2_{s}}\right. \\
& \left.+\tilde{\phi}_{2_{t_{0}+s}}, \ldots, y_{k_{s}}+\widetilde{\phi}_{k_{t_{0}+s}}\right) \mid d s \\
& \leq \frac{M_{i}}{\Gamma\left(\alpha_{i}\right)}\left(\int_{0}^{t_{1}}\left[\left(t_{1}-s\right)^{\alpha_{i}-1}-\left(t_{2}-s\right)^{\alpha_{i}-1}\right]^{1 /\left(1-\alpha_{i 1}\right)} d s\right)^{1-\alpha_{i 1}} \\
& +\frac{M_{i}}{\Gamma\left(\alpha_{i}\right)}\left(\int_{t_{1}}^{t_{2}}\left[\left(t_{2}-s\right)^{\alpha_{i}-1}\right]^{1 /\left(1-\alpha_{i 1}\right)} d s\right)^{1-\alpha_{i 1}} \\
& \leq \frac{M_{i}}{\Gamma\left(\alpha_{i}\right)}\left(\int_{0}^{t_{1}}\left[\left(t_{1}-s\right)^{\beta_{i}}-\left(t_{2}-s\right)^{\beta_{i}}\right] d s\right)^{1-\alpha_{i 1}} \\
& +\frac{M_{i}}{\Gamma\left(\alpha_{i}\right)}\left(\int_{t_{1}}^{t_{2}}\left(t_{2}-s\right)^{\beta_{i}} d s\right)^{1-\alpha_{i 1}} \\
& \leq \frac{M_{i}}{\Gamma\left(\alpha_{i}\right)\left(1+\beta_{i}\right)^{1-\alpha_{i 1}}}\left(t_{1}^{1+\beta_{i}}-t_{2}^{1+\beta_{i}}+\left(t_{2}-t_{1}\right)^{1+\beta_{i}}\right)^{1-\alpha_{i 1}} \\
& +\frac{M_{i}}{\Gamma\left(\alpha_{i}\right)\left(1+\beta_{i}\right)^{1-\alpha_{i 1}}}\left(t_{2}-t_{1}\right)^{\left(1+\beta_{i}\right)\left(1-\alpha_{i 1}\right)} \\
& \leq \frac{2 M_{i}}{\Gamma\left(\alpha_{i}\right)\left(1+\beta_{i}\right)^{1-\alpha_{i 1}}}\left(t_{2}-t_{1}\right)^{\left(1+\beta_{i}\right)\left(1-\alpha_{i 1}\right)}
\end{aligned}
$$

for all $i=1,2, \ldots, k$. Thus, $\left\{U_{i 2} y: y \in E(\eta, \gamma)\right\}$ is equicontinuous. Moreover, it is clear that $U_{i 2}$ is continuous for all $i=1,2, \ldots, k$. This implies that $U$ is a completely continuous operator. Now, by using Krasnoselskii's fixed point theorem we get that $S+U$ has a fixed point on $E(\eta, \gamma)$ and so the problem (1) has a solution $x=\left(x_{1}, \ldots, x_{k}\right)$, where 
$x_{i}(t)=\phi_{i}(0)+y_{i}\left(t-t_{0}\right)$ for all $t \in\left[t_{0}, t_{0}+\eta\right]$ and $i=$ $1,2, \ldots, k$. result.

If we put $g_{i 1}=0$ for all $i=1,2, \ldots, k$, then we obtain next

Corollary 4. Suppose that there exist $\delta \in(0, a)$ and $\gamma \in$ $(0, \infty)$ such that conditions $\left(H_{1}\right)-\left(H_{3}\right)$ hold, $g_{i}$ is continuous for all $i=1,2, \ldots, k$, and $\left|g_{i}\left(t, \mathbf{x}_{\mathbf{t}}\right)-g_{i}\left(t, \mathbf{y}_{\mathbf{t}}\right)\right| \leq l_{i}\|x-y\|_{*}$ for all $x=\left(x_{1}, x_{2}, \ldots, x_{k}\right), y=\left(y_{1}, y_{2}, \ldots, y_{k}\right) \in A(\delta, \gamma)$, and $t \in I_{0}$, where $l_{i} \in(0,1)$ is a constant for all $i=1,2, \ldots, k$. Then the problem (1) has at least one solution on $\left[t_{0}, t_{0}+\eta\right]$ for some positive number $\eta$. result.

If we put $g_{i 2}=0$ for all $i=1,2, \ldots, k$, then we obtain next Corollary 5. Suppose that there exist $\delta \in(0, a)$ and $\gamma \in$ $(0, \infty)$ such that conditions $\left(H_{1}\right)-\left(H_{3}\right)$ hold, $g_{i}$ is completely continuous for all $i=1,2, \ldots, k$, and the family $\left\{t \vdash g_{i}\left(t, \mathbf{x}_{\mathbf{t}}\right)\right.$ : $\left.\left(x_{1}, x_{2}, \ldots, x_{k}\right) \in \Lambda\right\}$ is equicontinuous on $C\left(I_{0}, \mathbb{R}^{n}\right) \times$ $C\left(I_{0}, \mathbb{R}^{n}\right) \times \cdots \times C\left(I_{0}, \mathbb{R}^{n}\right)$ for all bounded set $\Lambda$ in $A(\delta, \lambda)$. Then the problem (1) has at least one solution on $\left[t_{0}, t_{0}+\eta\right]$ for some positive number $\eta$.

\section{Conclusions}

In this work, we study an initial value problem for a class of $k$-dimensional systems of fractional neutral functional differential equations by using Krasnoselskii's fixed point theorem. Our result generalizes some old related results in a sense.

\section{Conflict of Interests}

The authors declare that there is no conflict of interests regarding the publication of this paper.

\section{Acknowledgment}

The research of the second and third authors was supported by Azarbaidjan Shahid Madani University.

\section{References}

[1] R. P. Agarwal and B. Ahmad, "Existence theory for anti-periodic boundary value problems of fractional differential equations and inclusions," Computers \& Mathematics with Applications, vol. 62, no. 3, pp. 1200-1214, 2011.

[2] R. P. Agarwal, M. Belmekki, and M. Benchohra, "A survey on semilinear differential equations and inclusions involving Riemann-Liouville fractional derivative," Advances in Difference Equations, vol. 2009, Article ID 981728, 47 pages, 2009.

[3] R. P. Agarwal, M. Benchohra, and S. Hamani, "A survey on existence results for boundary value problems of nonlinear fractional differential equations and inclusions," Acta Applicandae Mathematicae, vol. 109, no. 3, pp. 973-1033, 2010.

[4] R. P. Agarwal, Y. Zhou, and Y. He, "Existence of fractional neutral functional differential equations," Computers \& Mathematics with Applications, vol. 59, no. 3, pp. 1095-1100, 2010.
[5] B. Ahmad, "Existence of solutions for fractional differential equations of order $q \in(2,3]$ with anti-periodic boundary conditions," Journal of Applied Mathematics and Computing, vol. 34, no. 1-2, pp. 385-391, 2010.

[6] B. Ahmad, "New results for boundary value problems of nonlinear fractional differential equations with non-separated boundary conditions," Acta Mathematica Vietnamica, vol. 36, no. 3, pp. 659-668, 2011.

[7] B. Ahmad and J. J. Nieto, "Existence results for a coupled system of nonlinear fractional differential equations with threepoint boundary conditions," Computers \& Mathematics with Applications, vol. 58, no. 9, pp. 1838-1843, 2009.

[8] C.-Z. Bai and J.-X. Fang, “The existence of a positive solution for a singular coupled system of nonlinear fractional differential equations," Applied Mathematics and Computation, vol. 150, no. 3, pp. 611-621, 2004.

[9] Z. Bai and H. Lü, "Positive solutions for boundary value problem of nonlinear fractional differential equation," Journal of Mathematical Analysis and Applications, vol. 311, no. 2, pp. 495-505, 2005.

[10] Z. Bai and W. Sun, "Existence and multiplicity of positive solutions for singular fractional boundary value problems," Computers \& Mathematics with Applications, vol. 63, no. 9, pp. 1369-1381, 2012.

[11] D. Baleanu, H. Mohammadi, and Sh. Rezapour, "Positive solutions of an initial value problem for nonlinear fractional differential equations," Abstract and Applied Analysis, vol. 2012, Article ID 837437, 7 pages, 2012.

[12] D. Baleanu, R. P. Agarwal, H. Mohammadi, and Sh. Rezapour, "Some existence results for a nonlinear fractional differential equation on partially ordered Banach spaces," Boundary Value Problems, vol. 2013, article 112, 2013.

[13] D. Baleanu, Sh. Rezapour, and H. Mohammadi, "Some existence results on nonlinear fractional differential equations," Philosophical Transactions of the Royal Society of London A, vol. 371, no. 1990, Article ID 20120144, 2013.

[14] D. Baleanu, H. Mohammadi, and Sh. Rezapour, "On a nonlinear fractional differential equation on partially ordered metric spaces," Advances in Difference Equations, vol. 2013, article 83, 2013.

[15] D. Baleanu, S. Z. Nazemi, and Sh. Rezapour, "The existence of positive solutions for a new coupled system of multiterm singular fractional integrodifferential boundary value problems," Abstract and Applied Analysis, vol. 2013, Article ID 368659, 15 pages, 2013.

[16] D. Baleanu, S. Z. Nazemi, and Sh. Rezapour, "Existence and uniqueness of solutions for multi-term nonlinear fractional integro-differential equations," Advances in Differential Equations, vol. 2013, article 368, 2013.

[17] D. Baleanu, S. Z. Nazemi, and Sh. Rezapour, "Attractivity for a $k$-dimensional system of fractional functional differential equations and global attractivity for a $k$-dimensional system of nonlinear fractional differential equations," Journal of Inequalities and Applications, vol. 4014, p. 31, 2014.

[18] M. Benchohra, S. Hamani, and S. K. Ntouyas, "Boundary value problems for differential equations with fractional order and nonlocal conditions," Nonlinear Analysis: Theory, Methods \& Applications, vol. 71, no. 7-8, pp. 2391-2396, 2009.

[19] R. C. Cascaval, E. C. Eckstein, C. L. Frota, and J. A. Goldstein, "Fractional telegraph equations," Journal of Mathematical Analysis and Applications, vol. 276, no. 1, pp. 145-159, 2002. 
[20] C. Cuevas and J. César de Souza, "Existence of S-asymptotically $\omega$-periodic solutions for fractional order functional integrodifferential equations with infinite delay," Nonlinear Analysis: Theory, Methods \& Applications, vol. 72, no. 3-4, pp. 1683-1689, 2010.

[21] C. Cuevas and J. C. de Souza, " $S$-asymptotically $\omega$-periodic solutions of semilinear fractional integro-differential equations," Applied Mathematics Letters of Rapid Publication, vol. 22, no. 6, pp. 865-870, 2009.

[22] C. Cuevas, M. Rabelo, and H. Soto, "Pseudo-almost automorphic solutions to a class of semilinear fractional differential equations," Communications on Applied Nonlinear Analysis, vol. 17, no. 1, pp. 33-48, 2010.

[23] M. A. Darwish and S. K. Ntouyas, "On initial and boundary value problems for fractional order mixed type functional differential inclusions," Computers \& Mathematics with Applications, vol. 59, no. 3, pp. 1253-1265, 2010.

[24] J. P. C. dos Santos and C. Cuevas, "A symptotically almost automorphic solutions of abstract fractional integro-differential neutral equations," Applied Mathematics Letters of Rapid Publication, vol. 23, no. 9, pp. 960-965, 2010.

[25] S. D. Eidelman and A. N. Kochubei, "Cauchy problem for fractional diffusion equations," Journal of Differential Equations, vol. 199, no. 2, pp. 211-255, 2004.

[26] R. Gorenflo and F. Mainardi, "Fractional calculus: integral and differential equations of fractional order," in Fractals and Fractional Calculus in Continuum Mechanics, vol. 378, pp. 223276, Springer, New York, NY, USA, 1997.

[27] H. Hilfer, Applications of Fractional Calculus in Physics, World Scientific Publishing, Singapore, 2000.

[28] V. Lakshmikantham, "Theory of fractional functional differential equations," Nonlinear Analysis: Theory, Methods \& Applications, vol. 69, no. 10, pp. 3337-3343, 2008.

[29] V. Lakshmikantham and J. V. Devi, "Theory of fractional differential equations in a Banach space," European Journal of Pure and Applied Mathematics, vol. 1, no. 1, pp. 38-45, 2008.

[30] J. A. Tenreiro MacHado, M. F. Silva, R. S. Barbosa et al., "Some applications of fractional calculus in engineering," Mathematical Problems in Engineering, vol. 2010, Article ID 639801, 34 pages, 2010.

[31] K. S. Miller and B. Ross, An Introduction to the Fractional Calculus and Fractional Differential Equations, John Wiley \& Sons, New York, NY, USA, 1993.

[32] H. Mohammadi and Sh. Rezapour, "Existence results for nonlinear fractional differential equations on ordered gauge spaces," Journal of Advanced Mathematical Studies, vol. 6, no. 2, pp. 154158, 2013.

[33] S. K. Ntouyas and M. Obaid, "A coupled system of fractional differential equations with nonlocal integral boundary conditions," Advances in Difference Equations, vol. 2012, article 130, 2012.

[34] I. Podlubny, Fractional Differential Equations, vol. 198, Academic Press, New York, NY, USA, 1999.

[35] X. Su, "Boundary value problem for a coupled system of nonlinear fractional differential equations," Applied Mathematics Letters of Rapid Publication, vol. 22, no. 1, pp. 64-69, 2009.

[36] Y. Zhou, F. Jiao, and J. Li, "Existence and uniqueness for $p$-type fractional neutral differential equations," Nonlinear Analysis: Theory, Methods \& Applications, vol. 71, no. 7-8, pp. 2724-2733, 2009.
[37] Y. Zhou, F. Jiao, and J. Li, "Existence and uniqueness for fractional neutral differential equations with infinite delay," Nonlinear Analysis: Theory, Methods \& Applications, vol. 71, no. 7-8, pp. 3249-3256, 2009.

[38] D. R. Smart, Fixed Point Theorems, Cambridge University Press, New York, NY, USA, 1974. 


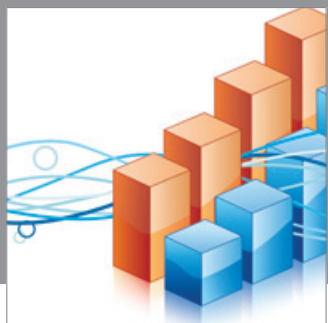

Advances in

Operations Research

mansans

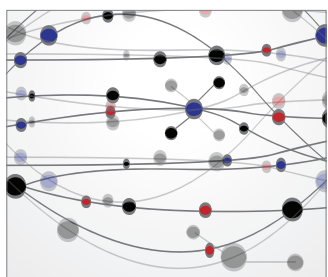

The Scientific World Journal
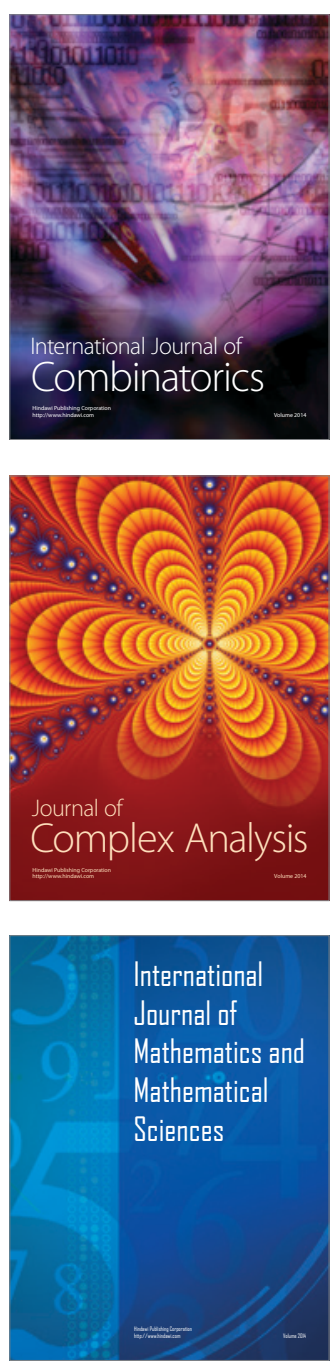
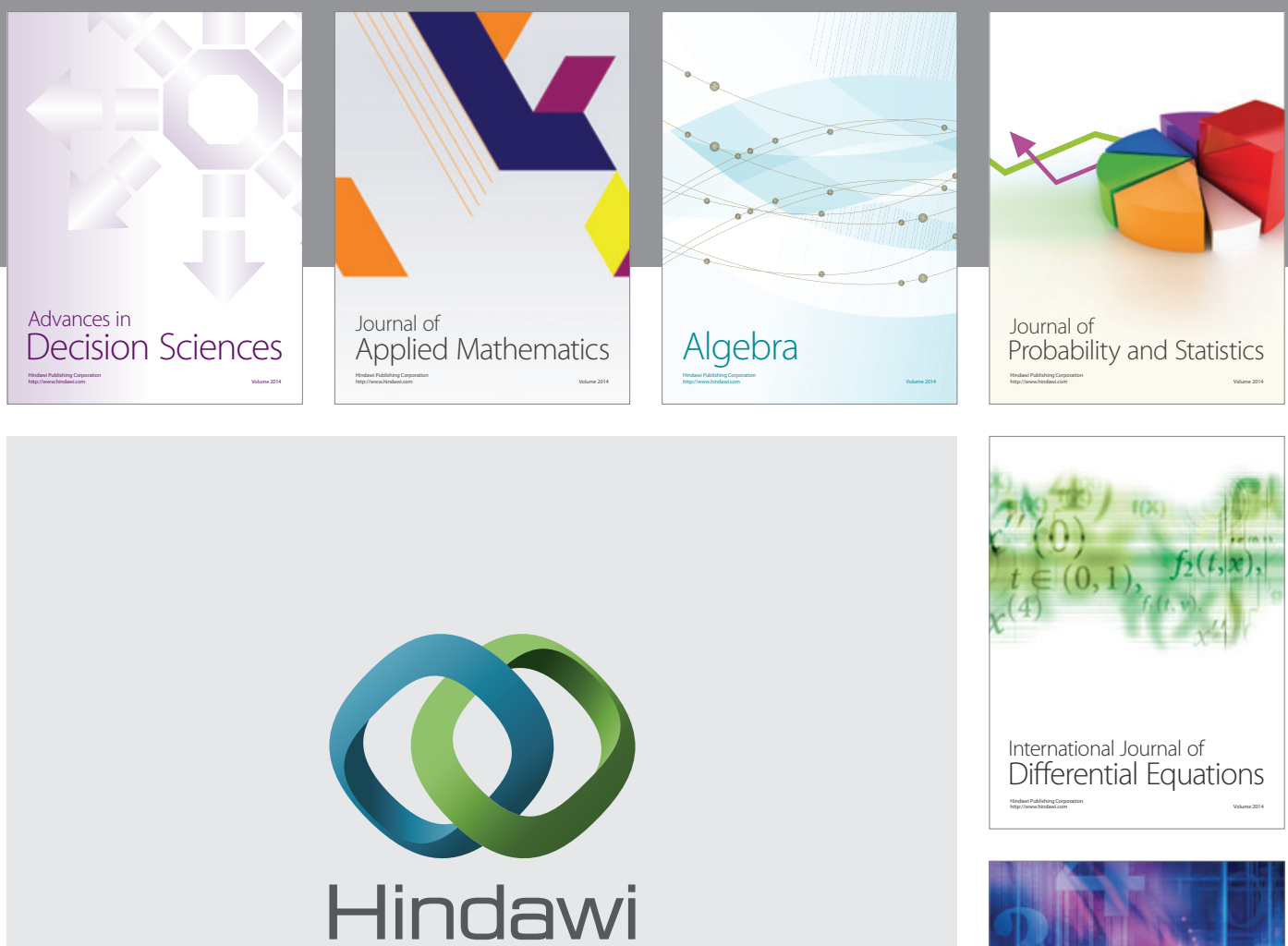

Submit your manuscripts at http://www.hindawi.com
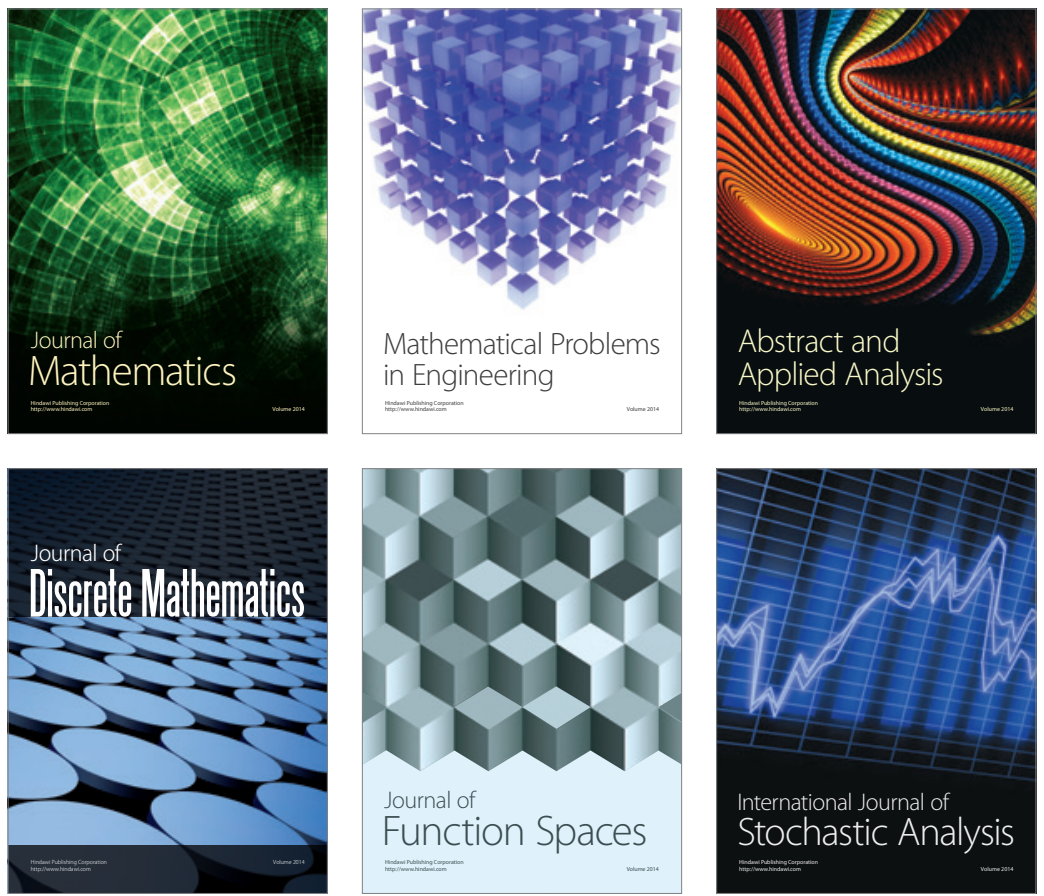

Journal of

Function Spaces

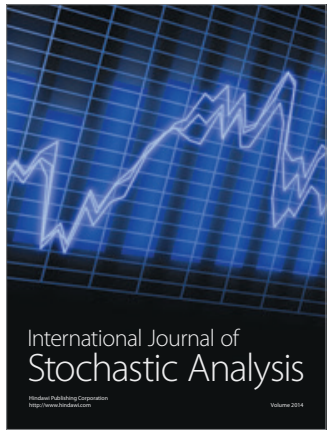

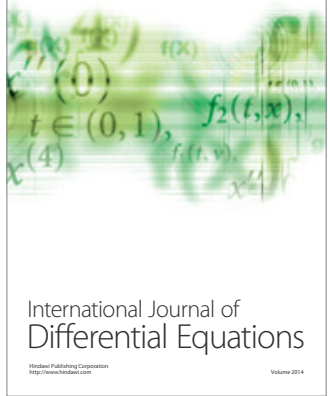
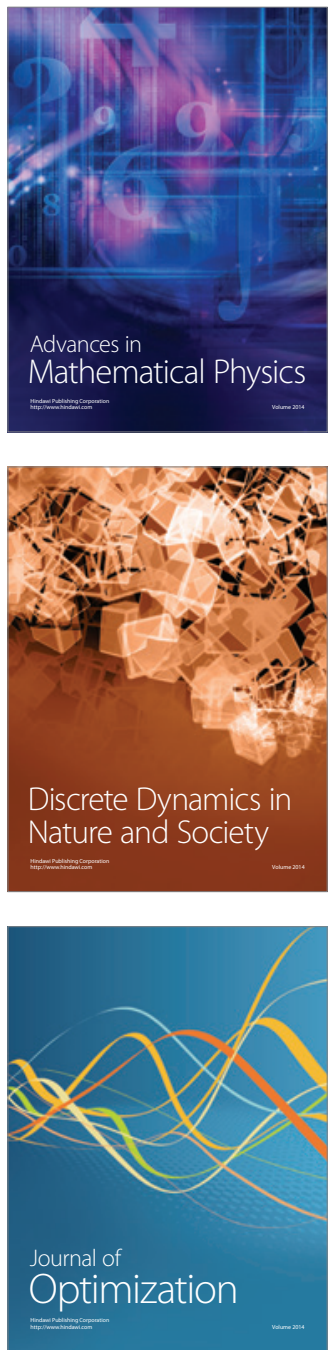